\title{
Designs Neuro-Fuzzy Models in Control Problems of a Steam Heater
}

\author{
Siddikov Isamidin Xakimovich, ${ }^{1, *}$, Bakhrieva Xurshida Askarxodjaevna² \\ ${ }^{1}$ Department of Information Processing Systems and Management, Tashkent State Technical University, Uzbekistan \\ ${ }^{2}$ Scientific-innovative Center of Information and Communication Technologies, \\ Tashkent University of Information Technologies, Uzbekistan
}

Received October 7, 2019; Revised November 26, 2019; Accepted December 5, 2019

Copyright $\bigcirc 2019$ by authors, all rights reserved. Authors agree that this article remains permanently open access under the terms of the Creative Commons Attribution License 4.0 International License

\begin{abstract}
The article deals with the design of neuro-fuzzy models in the tasks of creating a system of automatic control by technological processes of steam-generating heat engines. A methodology has been developed for creating a temperature control system for a superheated operating under a priori uncertainties. Such control systems relate to adaptive systems capable of controlling the object with significant, previously unknown, changes in the parameters of the object. The use of an artificial neuron is proposed as adaptive regulation. A fuzzy model of the proportional-integral-differential-regulator adapter has been developed, an automatic control system based on the Mamdani algorithm. The proposed method for constructing an adaptive controller makes it possible to exclude the active identification stage from the automatic tuning process and the associated deterioration in the operation of the regulatory object. The feasibility and effectiveness of the method is proven experimentally. Computer testing of the obtained model in uncertain conditions was carried out, when the values of the transfer function of a complex control object changed. Regulation is carried out on the basis of the proposed hybrid high-speed algorithm of fuzzy-logical derivation of the main parameters: vapor pressure and temperature. The algorithm for setting the weight coefficients of the neuron is presented. The use of an adaptive fuzzy-logical controller allows us to provide a fairly good quality of controlling the temperature of superheated steam. To create process control algorithms, a hybrid application of a neural network and fuzzy logic is proposed, which allows taking into account the uncertainty of changes in the parameters of the object and the environment. The results can be used in the development of adaptive control systems and other heat power devices.
\end{abstract}

Keywords ACS, PID Controller, Nonlinearity, Neuro-Fuzzy, Algorithm, Hypersurface, Procedure,
System, Superheater, Pressure, Temperature

\section{Introduction}

The quality of the developed systems of automatic control of technological processes is largely determined by the usefulness of the mathematical models used in the control of technological objects. The steam generating heat engines under consideration are the technological basis of many industrial facilities. This role requires close attention from both technologists and industrial automation specialists, because modern technological progress requires ensuring the optimal operation of equipment, reducing energy consumption, increasing reliability, efficiency, environmental friendliness with an increase in efficiency.

\section{Materials and Methods}

A steam boiler as an object of regulation is a complex dynamic system with a large number of input and output interrelated quantities, therefore, examining it, in most cases they are decomposed into separate sections of regulation. At the same time, the influence of other circuits on the studied one is automatically excluded, which complicates the task of practical application of the newly developed control algorithms. Proceeding from this, it is proposed to use a complex mathematical model of object dynamics to study the synthesized algorithms and control systems, which allows one to take into account the mutual influence of control loops through the object and bring the behavior of the tested system closer to industrial realities. From a technological point of view, the task of controlling a superheater is to provide a given temperature in the steam 
path of the boiler. The temperature regime is ensured by increasing or decreasing the amount of water injected into the desuperheater. In the existing power system, a typical automatic control scheme is mainly used, which is called the cascade temperature control system for superheated steam, the control circuit of which includes a PI controller and a correction device $[8,13]$. The practice of operating such a system shows that with significant changes in the task, i.e. the desired values of the parameters of the temperature regime, there is a need to reconfigure the values of the coefficients of its control loop. In fact, this is an important objective sign that the functioning of the control system proceeds under conditions of a priori uncertainty. Indeed, the analysis of the operational characteristics of the superheater shows that the control object has a variable value of transport delay, its dynamic properties substantially depend on the oxygen content in the exhaust gases, steam consumption, heating surface contamination, as well as on operational factors - load, type and type of fuel burned, conditions of heating surfaces, excess air, etc. [1]. In addition [11], obtaining a mathematical model of a superheater is usually associated with the use of experimental methods, in particular, the method of acceleration curves, and, as a result, the mathematical description a priori becomes inaccurate. Thus, the development of a temperature control system for a superheater operating under conditions of a priori uncertainty is expediently carried out using adaptive control methods.

\section{Solution Method}

In the work, to adapt the parameters of the regulator, a mathematical apparatus is proposed. When constructing the circuit of the main control loop, we will consider a superheater together with a thermocouple as a control object (Fig. 1). Transfer function $W_{O Y}(s)$, obtained as a result of processing the family of acceleration curves [9.11], we write in the following form:

$$
W_{O Y}(s)=\frac{y(s)}{v(s)}=\frac{K \cdot e^{-s h}}{a_{3} \cdot s^{3}+a_{2} \cdot s^{2}+a_{1} \cdot s+1} \cdot \frac{m_{T X K}}{T_{T X K} \cdot s+1}
$$

where $s$ is a complex variable; $y(s)$ and $v(s)$ - mages of scalar functions of the output and input of the object; $K$-is the injection coefficient; $h$-is the transport delay; $a_{1}, a_{2}, a_{3}$ - parameters of the characteristic equation of the function $W_{O Y}(s), T_{T X K}=$ const and $m_{T X K}=$ const - time constant and static coefficient of the chromel-kopel thermocouple.

The level of a priori parametric uncertainty in the object (1), following, we will set the relations:

$$
\begin{gathered}
2.8=K^{(-)} \leq K \leq K^{(+)}=4.6, \\
45=h^{(-)} \leq h \leq h^{(+)}=141, \\
15=T_{T X K^{(-)}} \leq T_{T X K} \leq T_{T X K^{+}}=20, \\
244=a_{1}{ }^{(-)} \leq a_{1} \leq a_{1}{ }^{(+)}=393, \\
20160=a_{2}{ }^{(-)} \leq a_{2} \leq a_{2}{ }^{(+)}=3909600
\end{gathered}
$$

and

$$
\xi=\operatorname{col}\left(K, h, T_{T X K}, a_{1}, a_{2}, a_{3}\right) \in \Xi,
$$

where are superscripts ${ }^{(-)}$and ${ }^{(+)}-$the values of the boundaries of the coefficients that determine the known set $\Xi ; \in \xi \quad \Xi$-vector of unknown parameters.

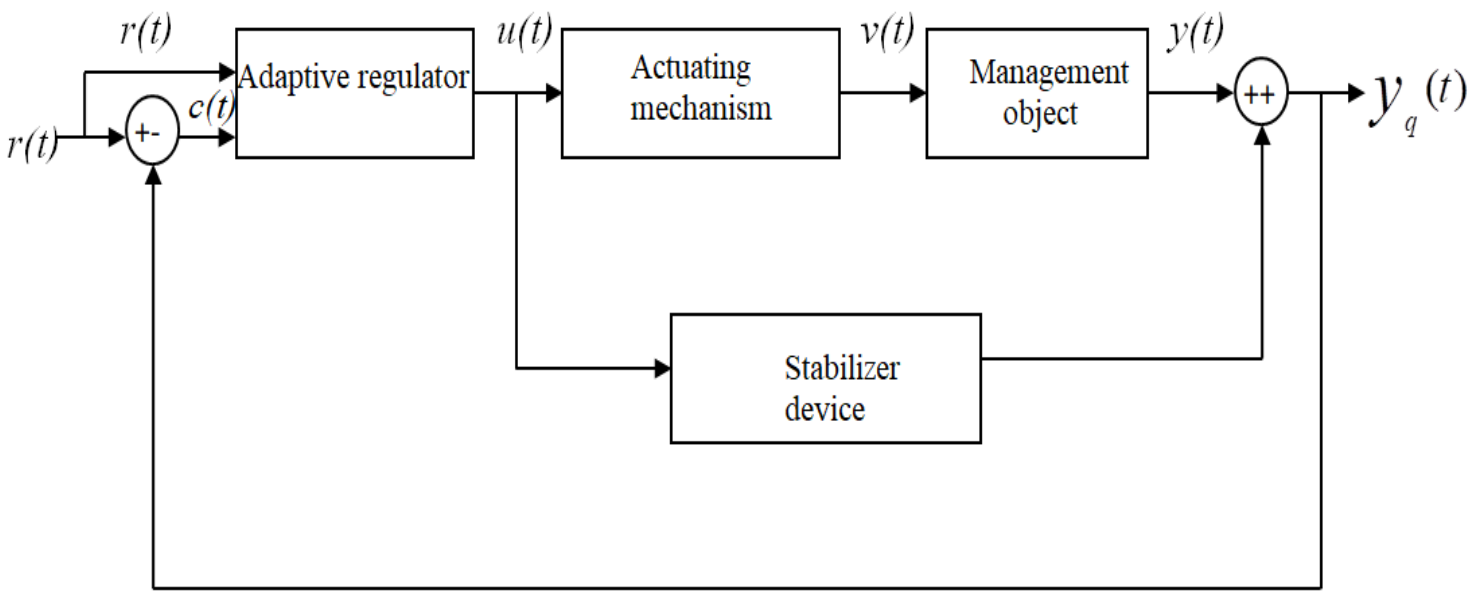

Figure 1. The main temperature control circuit of the superheater 
The transfer function of the actuator (moving the control body of the control object - the valve), given its low inertia with respect to the object, we will describe in the form

$$
W(s)=\frac{v(s)}{u(s)}=\frac{1}{T_{\text {им }} \cdot S}
$$

where $\mathrm{T}_{\text {ИМ }}=$ const - actuator time constant. In order to give the linear part of the control system the desired properties, we similarly introduce a stabilizing device into the main circuit with the following description:

$$
q(s)=\frac{K_{1} \cdot\left(T_{1} \cdot s+1\right)}{\left(T_{2} \cdot s+1\right) \cdot\left(T_{3} \cdot s+1\right)} \cdot u(s)
$$

where $K_{1}$ and $T_{1}, T_{2}, T_{3}$ - gear ratio and time constants of the stabilizing device. The structure of the adaptive controller is set in the form

$$
\begin{aligned}
& u(s)=\frac{K_{2} \cdot s}{T_{0} \cdot s+1} \cdot g(s) \\
& g(t)=\wp(t) \cdot r(t) ; \\
& \wp(t)=f\left(e(t), r^{*}\right)=\frac{1}{1+e^{-\alpha \cdot\left(w \cdot e(t)+w_{0}\right)}} ; \\
& r(t)=r^{*}=\text { const; } \\
& e(t)=r *-y_{q}(t)=r *-y(t)-q(t),
\end{aligned}
$$

where $K_{2}$ and $T_{0}$ - gear ratio and time constant of the linear part of the adaptive controller; $u(s)$ - control action; $g(t)$ - output of the nonlinear part of the adaptive controller represented by one neuron with a sigmoid activation function $\wp(t)$ and weights $w$ and $w_{0}$. The neuron input is a generalized control error $e(t) ; r(t)-$ setpoint equal in stabilization mode to $r^{*} ; y_{q}(t)-$ generalized output of a control system of the form $y_{q}(t)=y(t)+q(t)$.

To control complex, poorly formalized technological processes of the power system, fuzzy logic controllers based on linguistic information are widely used.This approach is applied to regulating the parameters of the boiler in conditions of uncertainty. In these objects, the collection of necessary statistical information is difficult due to the lack or absence of measuring instruments of some higher orders. Therefore, the application of methods of probability theory does not give the required results, it is in connection with this that the use of the theory of fuzzy sets is proposed.

The fuzzy logic controller algorithm uses the following four variables that describe the process being controlled: $\mathrm{P}_{\mathrm{E}}$ - the pressure deviation in the steam boiler, defined as the difference between the current value and the pre-selected value corresponding to the norm; $S_{E}-$ rate of change $P_{E}$; $\mathrm{C}_{\mathrm{PE}}$ - change in pressure deviation, defined as the difference between the current pressure $\mathrm{P}_{\mathrm{E}}$ and the pressure value obtained in the previous measurement; $\mathrm{C}_{\mathrm{EE}}$ deviation rate change $\mathrm{C}_{\mathrm{PE}}$.

Regulation is carried out according to two algorithms: the degree of steam heating is adjusted one at a time, i.e. the pressure is regulated $\left(\mathrm{H}_{\mathrm{C}}\right.$ - heating change), differently changes the position of the throttle ( $\mathrm{T}_{\mathrm{C}}$ - throttle position). Each algorithm takes into account all the above variables. The linguistic rules that describe the control algorithm are determined in advance by an experienced person - the operator.

Variable $\mathrm{H}_{\mathrm{C}}$ - was represented by a discrete set of values from 32 points, and $T_{C}$ - ten points. Variables $C_{P E}, P_{E}, C_{E}$ ${ }_{E}, S_{E}$ represented 13 points evenly distributed between the maximum positive and negative values.

To describe the values of variables by a human operator, the following linguistic values were used (abbreviated names correspond to the first letters of words in English):PB- big positive, PM- positive average, PS - small positive, NO - zero, NS- small negative, NM- average negative, NB- big negative.

For these fuzzy parameters, we construct an membership function of exponential type. Variable $\mathrm{P}_{\mathrm{E}}$ and $\mathrm{S}_{\mathrm{E}}$ negative values close to zero are additionally highlighted (below normal - NO) and positive, close to zero values (above normal- PO). Along with the indicated subsets, a fuzzy value was used to estimate the values of variables ANY, described by such a membership function, which is equal to unity for any element. Complex values based on the specified values were obtained through the operation AND, OR, NOT. Management rules were formulated as conditional sentences, for example, "if $\mathrm{P}_{\mathrm{E}}=\mathrm{NB}$, then $\mathrm{H}_{\mathrm{C}}=\mathrm{P}_{\mathrm{B}}$ ". The above conditional clause defines the relationship between two fuzzy variables $\mathrm{P}_{\mathrm{E}}$ and $\mathrm{H}_{\mathrm{C}}$, which is described by the Cartesian product of two fuzzy subsets $\mathrm{NB}$ and PB. It is convenient to represent the Cartesian product as a matrix of $n$ columns and $m$ rows, where $m$ and $\mathrm{n}$ are the number of elements of universes for subsets NB and $\mathrm{PB}$. Assume that the relation $\mathrm{R}$ between the variables is known $\mathrm{PE}$ and $\mathrm{HC}$, then for some value you can determine the output value using the composition rule $\mathrm{y}=\mathrm{x}$ o R. For conditional expressions "if A, then (if B then C)" the Cartesian product is determined $\mathrm{A} \times \mathrm{B} \times \mathrm{C}$, which is used to determine the output $C^{\prime}$ 'at the inputs $A^{\prime}$ and $B^{\prime}: C^{\prime}=\left(A^{\prime} x\right.$ $\left.\mathrm{B}^{\prime}\right)$ o $(\mathrm{A} \times \mathrm{B} \times \mathrm{C})$.

In the described algorithm, two or more rules were combined with the help of a bundle ELSE, which was interpreted as the operation max.

For example, "if $\mathrm{P}_{\mathrm{E}}=\mathrm{NB}$ and $\mathrm{C}_{\mathrm{PE}}=\mathrm{NOT}(\mathrm{NB}$ or $\mathrm{NM})$ and $\mathrm{S}_{\mathrm{E}}=\mathrm{ANY}$, then $\mathrm{H}_{\mathrm{C}}=\mathrm{PM}$, otherwise if $\mathrm{P}_{\mathrm{E}}=\mathrm{NB}$ and $\mathrm{C}_{\mathrm{PE}}=\mathrm{NC}$ and $\mathrm{S}_{\mathrm{E}}=\mathrm{ANY}$ and $\mathrm{C}_{\mathrm{EE}}=\mathrm{ANY}$, then $\mathrm{H}_{\mathrm{C}}=\mathrm{PM}$, otherwise, if ...".

Both algorithms, the pressure control algorithm and the speed control algorithm (throttle), are given in [2] in the 
form of complex conditional expressions. Here is a complete description of the pressure control algorithm: if $\mathrm{P}_{\mathrm{E}}=\mathrm{NB}$, then (if $\mathrm{C}_{\mathrm{PE}}=\mathrm{NOT}(\mathrm{NB}$ or $\mathrm{NM})$, then $\left.\mathrm{H}_{\mathrm{C}}=\mathrm{PB}\right)$; if $\mathrm{P}_{\mathrm{E}}=\left(\mathrm{NB}\right.$ then $\mathrm{NM}$ ), then (if $\mathrm{C}_{\mathrm{PE}}=\mathrm{NC}$, then $\left.\mathrm{H}_{\mathrm{C}}=\mathrm{PM}\right)$; if $\mathrm{P}_{\mathrm{E}}=\mathrm{NS}$, then (if $\mathrm{C}_{\mathrm{PE}}=\mathrm{PS}$ or $\mathrm{NO}$, then $\mathrm{H}_{\mathrm{C}}=\mathrm{PM}$ ); if $\mathrm{P}_{\mathrm{E}}=\mathrm{NO}$, then (if $\mathrm{C}_{\mathrm{PE}}=(\mathrm{PB}$ or $\mathrm{PM})$, then $\mathrm{H}_{\mathrm{C}}=\mathrm{PM}$ ); if $\mathrm{P}_{\mathrm{E}}=\mathrm{NO}$, then (if $\mathrm{C}_{\mathrm{PE}}=(\mathrm{NB}$ or $\mathrm{NM})$, then $\left.\mathrm{H}_{\mathrm{C}}=\mathrm{NM}\right)$; if $\mathrm{P}_{\mathrm{E}}=(\mathrm{PO}$ or $\mathrm{NO})$, then (if $\mathrm{C}_{\mathrm{PE}}=\mathrm{NO}$, then $\left.\mathrm{H}_{\mathrm{C}}=\mathrm{NO}\right)$; if $\mathrm{P}_{\mathrm{E}}=\mathrm{PO}$, then (if $\mathrm{C}_{\mathrm{PE}}=(\mathrm{NB}$ or $\mathrm{NM})$, then $\mathrm{H}_{\mathrm{C}}=\mathrm{PM}$ ); if $\mathrm{P}_{\mathrm{E}}=\mathrm{PO}$, then (if $\mathrm{C}_{\mathrm{PE}}=(\mathrm{PB}$ or $\mathrm{PM})$, then $\left.\mathrm{H}_{\mathrm{C}}=\mathrm{NM}\right)$; if $\mathrm{P}_{\mathrm{E}}=\mathrm{PS}$, then (if $\mathrm{C}_{\mathrm{PE}}=\left(\mathrm{PS}\right.$ or $\mathrm{NO}$ ), then $\left.\mathrm{H}_{\mathrm{C}}=\mathrm{NM}\right)$; if $\mathrm{P}_{\mathrm{E}}=\mathrm{PB}$ or $\mathrm{PM}$, then (if $\mathrm{C}_{\mathrm{PE}}=\mathrm{NS}$, then $\mathrm{H}_{\mathrm{C}}=\mathrm{NM}$ ); if $\mathrm{P}_{\mathrm{E}}=\mathrm{PB}$, then (if $\mathrm{C}_{\mathrm{PE}}=\mathrm{NOT}(\mathrm{NB}$ or $\mathrm{NM})$, then $\left.\mathrm{H}_{\mathrm{C}}=\mathrm{NB}\right)$; if $\mathrm{P}_{\mathrm{E}}=\mathrm{NO}$, then (if $\mathrm{C}_{\mathrm{PE}}=\mathrm{PS}$, then $\mathrm{H}_{\mathrm{C}}=\mathrm{PS}$ ); if $\mathrm{P}_{\mathrm{E}}=\mathrm{NO}$, then (if $\mathrm{C}_{\mathrm{PE}}=\mathrm{NS}$, then $\mathrm{H}_{\mathrm{C}}=\mathrm{NS}$ ); if $\mathrm{P}_{\mathrm{E}}=\mathrm{PO}$, then (if $\mathrm{C}_{\mathrm{PE}}=\mathrm{NS}$, then $\mathrm{H}_{\mathrm{C}}=\mathrm{PS}$ ); if $\mathrm{P}_{\mathrm{E}}=\mathrm{PO}$, then (if $\mathrm{C}_{\mathrm{PE}}=$, PS then $\mathrm{H}_{\mathrm{C}}=\mathrm{NS}$ ).

Similarly, a speed control algorithm is compiled.

\section{The Formulation of the Synthesis Problem}

With a known level of a priori uncertainty of the form (2) given relative to the object coefficients (1) for the control

$$
y_{q}(s)=\frac{K_{1}}{T_{0} \cdot s+1} \cdot\left\{\frac{K \cdot m_{T X K} \cdot T_{U M}^{-1} \cdot e^{-s \cdot h}}{\left(a_{3} \cdot s_{3}+a_{2} \cdot s_{2}+a_{1} \cdot s+1\right) \cdot\left(T_{T X K} \cdot s+1\right)}+\frac{K_{1} \cdot s \cdot\left(T_{1} \cdot s+1\right)}{\left(T_{2} \cdot s+1\right) \cdot\left(T_{3} \cdot s+1\right)}\right\} \cdot g(s),
$$

it is obvious that the systems of equations (1), (3) - (7) and (6), (7), (10) will be equivalent.

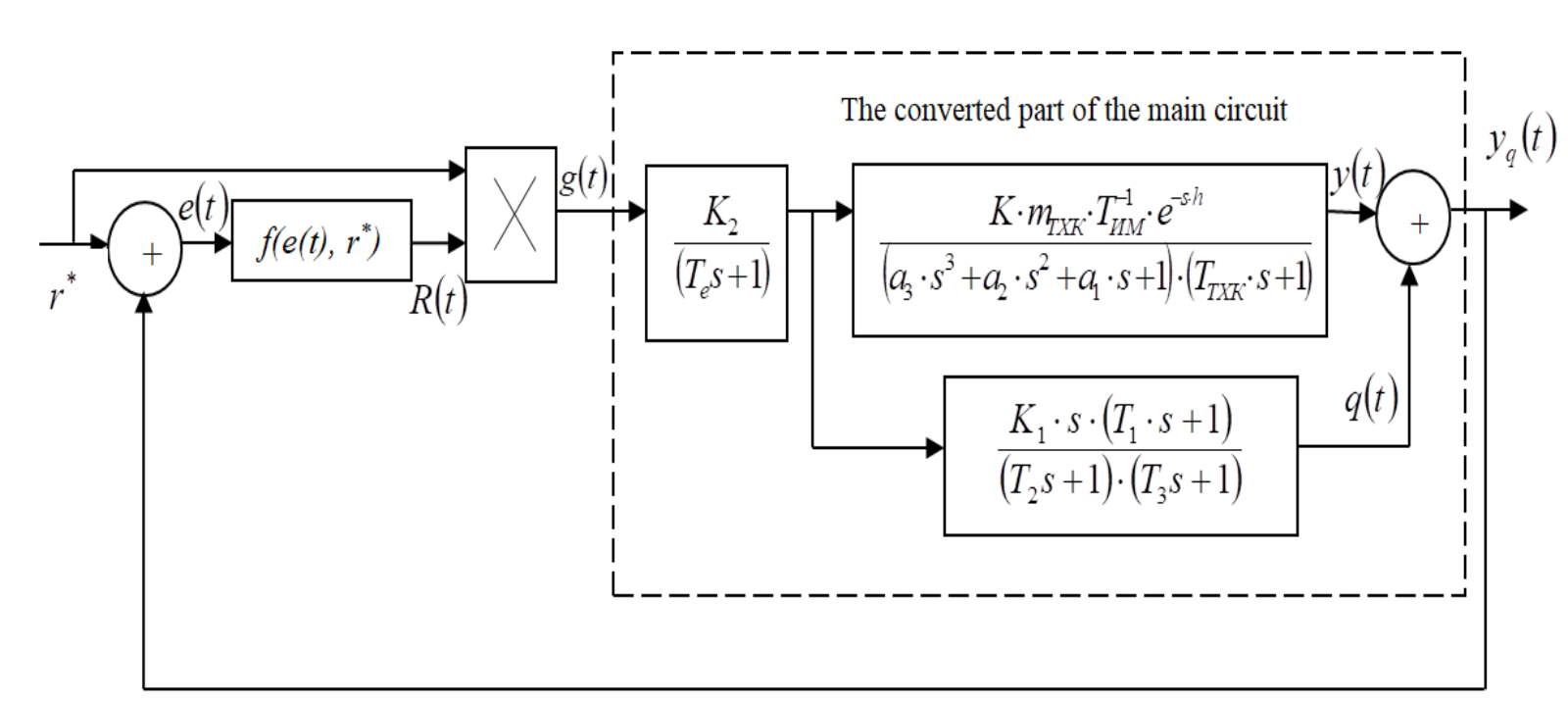

Figure 2. The equivalent structural diagram of the control system (1), (3) - (7) system (1), (3) - (7), it is required to determine the explicit form of the self-tuning algorithm of the nonlinear part of controller (7) - a neuron, an adaptive controller (6) so that under any initial conditions and an arbitrary set of vector values $\xi \in \Xi$, satisfying inequalities (2), the following would be achieved:

firstly, management goals

$$
\lim _{t \rightarrow \infty} y(t)=y^{*}=r *=\text { const; }
$$

secondly, adaptation goals

$$
\lim _{t \rightarrow \infty} \wp(t)=\wp_{0}=\text { const; }
$$

\section{Algorithm for Setting the Weight Coefficients of the Neuron}

We perform the identical transformation of the linear part of the control system (1), (3-7). Since for the equivalently transformed linear part of the main loop of the control system (1), (3) - (7) (see the selected fragment of the structural diagram in Fig. 2), we can write the equation 
If we assume that in system (6), (7), (10), target conditions (8), (9) are attainable, then in the steady-state mode of the stabilization process, the system is described by the equations

$$
\begin{gathered}
y_{q^{*}}=K_{2} \cdot K \cdot m_{T X K} \cdot T_{U M^{-1}} \cdot g, \\
g^{*}=\wp_{0} \cdot r^{*}, \\
\wp_{0}=f\left(e^{*}, r^{*}, \infty\right), g^{*}=0, e^{*}=r^{*}-y_{q^{*}}=r^{*}-y^{*}=0,
\end{gathered}
$$

where the index $*$ is the designation of the steady-state values of the corresponding variables. Equations (11) - (13) can be combined and represented identically in the form of the expression

$$
y_{q^{*}}=K_{2} \cdot K \cdot m_{T X K} \cdot T_{\text {ИM }} \wp_{0} \cdot r^{*},
$$

which is often called the implicit reference model equation. In particular, from (14) it follows, given the equality $y_{q^{*}}=r^{*}$, what's the meaning $\wp_{0}=$ const always exists and is defined by the expression

$$
\wp_{0}=\frac{T_{И M}}{K_{2} \cdot K \cdot m_{T X K}} .
$$

Carried out, the adjustment of the adaptive fuzzy controller may be an algorithm for the back propagation of errors to adjust the weight coefficients of artificial neural networks.

Output signal $\wp(\tau)$ neuron at the $\tau$-th moment of time $(\tau=1,2, \ldots)$ is defined as

$$
\wp(\tau)=f(\sigma(\tau))=\frac{1}{1+e^{-\alpha \sigma(\tau)}},
$$

Moreover

$$
\sigma(\tau)=W_{O}+W(\tau) \cdot e(\tau)
$$

Thus we get a lot of output signals

$$
\wp_{1}\left(\tau_{1}\right), \ldots, \wp_{i}\left(\tau_{i}\right), \ldots \wp_{n}\left(\tau_{n}\right),
$$

which, when fulfilling (8), should correspond to the reference value of the output signal a $\wp_{0}=$ const, i.e.

$$
\lim _{n \rightarrow \infty} \wp_{n}\left(\tau_{n}\right)=\wp_{0}=\text { const } .
$$

In our case, the reference output signal will be (15), and the reference input signal $-\mathrm{e}^{*}=0$.

We can formulate a measure of error based on a comparison of signals (15) and (18) in the form of a half-sum of squares of differences

$$
\mathrm{E}(\tau)=\frac{1}{2}[\varepsilon(\tau)]^{2}=\frac{1}{2}\left[\wp_{0}-\wp(\tau)\right]^{2}
$$

To correct the weight coefficient $\mathrm{w}$, you can use the rule of steepest descent, which in our case takes the form

$$
w(\tau+1)=w(\tau)+\gamma \frac{d E(\tau)}{d w(\tau)},
$$

where, $\gamma>0$ determines the size of the correction step. Note that

$$
\frac{d E(\tau)}{d w(\tau)}=\frac{d E(\tau)}{d \sigma(\tau)} \frac{d \sigma(\tau)}{d w(\tau)}=\frac{d E(\tau)}{d \sigma(\tau)} e(\tau) .
$$

We introduce the notation

$$
\delta(\tau)=\frac{d E(\tau)}{d \sigma(\tau)}
$$

then algorithm (20) takes the form

$$
W(\tau+1)=W(\tau)+\gamma \cdot \delta(\tau) e(\tau)
$$

The calculation method $\delta(\tau)$ is as follows

$$
\begin{aligned}
& \delta(\tau) \frac{d E(\tau)}{d \sigma(\tau)}=\frac{1}{2} \frac{d}{d \sigma(\tau)}\left([\varepsilon(\tau)]^{2}\right)=\frac{1}{2} \frac{d}{d \sigma(\tau)}\left(\left[\wp_{0}-\wp(\tau)\right]^{2}\right)= \\
& =-\left(\wp_{0}-\wp(\tau)\right) f_{\sigma}^{\prime}(\sigma(\tau))=-\left(\wp_{0}-\wp(\tau)\right)(1-\wp(\tau)) \wp(\tau) .
\end{aligned}
$$

Given (24), the algorithm for setting the weight coefficient of the neuron

$$
W(\tau+1)=W(\tau)-\gamma\left(\wp_{0}-\wp(\tau)\right) \cdot \wp(\tau) e(\tau)
$$

and the weight coefficient $w_{0}$ of the neuron

$$
W_{O}(\tau+1)=W_{O}(\tau)-\gamma\left(\wp_{0}-\wp(\tau)\right)(1-\wp(\tau)) \cdot \wp(\tau) .
$$

Finally, subject to (15)

$$
w(\tau+1)=w(\tau)-\gamma\left(\frac{T_{\text {ИM }}}{K_{2} \cdot K \cdot m_{T X K}}-\wp(\tau)\right)(1-\wp(\tau)) \wp(\tau) e(\tau),
$$

$$
w_{0}(\tau+1)=w_{0}(\tau)-\gamma\left(\frac{T_{U M}}{K_{2} \cdot K \cdot m_{T X K}}-\wp(\tau)\right)(1-\wp(\tau)) \wp(\tau) .
$$

The use of an adaptive fuzzy-logical controller allows you to provide a fairly good quality control of the temperature of superheated steam. The error back propagation algorithm for setting the weight coefficient of one neuron or the set of weight coefficients of an artificial neural network can be used as an algorithm for adapting a control system in conditions of significant a priori uncertainty or partial change in the parameters of the control object.

The key advantage of the model is the possibility of its implementation on industrial software and hardware complexes (PTC) with physical inputs and outputs. The 
model performs computational operations to calculate the values of technological parameters. Further, these values are transferred to the SCADA-system, which provides the output of information on the screen of the stand operator. In turn, the programmable logic controller (PLC) in accordance with the laid down algorithms generates control actions on the object, and also transfers data to the upper level.

\section{The Results of the Study}

The synthesis of usable control systems is complicated by the change in the dynamic characteristics of individual elements of boiler units depending on the load and other factors, as well as the significant transport delay characteristic of the control circuits of heat and power processes. Thus, to ensure the required quality of control, the controller parameters must be changed in significant ranges. To analyze the dynamic properties of the above channels, the acceleration curves of the contours are approximated by inertial links of the first order with delay. As a result of the approximation, the obtained transfer functions $W(S)$.

Smoke exhaust performance - vacuum in the boiler furnace.

Air consumption - rarefaction boiler boiler

$$
W(S)=\frac{20.6 s+278}{0.0566 s^{2}+1.67 s+1}
$$

Fan Performance - Air Consumption

$$
W(S)=\frac{80.3 s+1080}{0.0566 s^{2}+1.67 s+1}
$$

Fan Performance - Air Pressure

$$
W(S)=\frac{0.5}{16 s+1}
$$

Air Consumption - Content

$$
O_{2} W(S)=\frac{2.74 s+0.224}{56 s^{2}+16 s+1}
$$

Fuel Consumption - Content

$$
O_{2} W(S)=\frac{-39.8}{56 s^{2}+16 s+1}
$$

Feed water supply - drum level

$$
W(S)=\frac{0.022}{s} e^{-20 s}
$$

Fuel Consumption - Drum Level

$$
W(S)=\frac{0.015}{60 s+1}+\frac{-1}{100 s+1}
$$

Steam flow rate - drum level $W(S)=\frac{0.26}{s} e^{-70 s}$

Amount of steam generated - pressure in the line $W(S)=\frac{1}{32 s+1}$

Amount of steam generated - consumption of consumed steam:

$$
W(S)=\frac{0.8}{28.25 s+1}+\frac{1}{43.67 s+1}
$$

Steam consumption - pressure in the line

$$
W(S)=\frac{30.03 s+1}{28.25 s+1}+\frac{40 s+1}{43.67 s+1}
$$

Steam consumption - consumption of consumed steam

$$
W(S)=0.0195 \frac{41 s}{41 s+1}
$$

Fuel Consumption - Fuel Pressure $W(S)=\frac{0.2}{20 s+1}$

Fuel Consumption - Firebox Thermal Perception $W(S)=\frac{0.5}{10 s+1}$

Fuel Consumption - Amount of Steam Generated $W(S)=\frac{0.6}{20 s+1}$

The physical implementation of the model is assigned to the industrial programmable logic controller of the modular type Phoenix Contact ILC. This allows you to bind the required number of logical inputs / outputs of the model to the physical unified controller interfaces, and, therefore, to external hardware in which control algorithms were implemented. The controller software implemented standard laws for controlling control loops. As a result of the work, the following transients were obtained, which are reflected in Figure. 3.

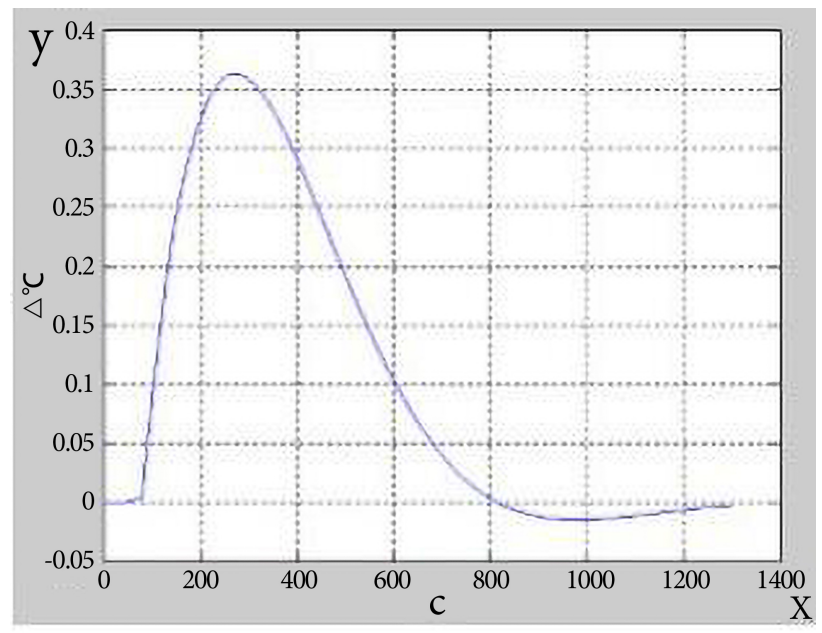

Figure. 3. Transient along the disturbance channel - output in the temperature control system of superheated steam 
Thus, control systems must determine the final settings of the regulators when commissioning an object, after its modification or a significant change in characteristics. In fact, automated adaptive control systems are used all the time, just the functions of the adaptation modules are performed by an experienced operator. Therefore, the development of systems that can independently or under the supervision of an operator adapt to changes in the control object is an urgent scientific and practical task. Maintaining high quality control of the circuits and components of the equipment helps to save resources and energy, increase the life of the equipment, will positively affect the overall work of controlled processes and engineering systems. And the solution to this problem is facilitated by bench research of the dynamics of the controlled facility as part of real industrial PTKs.

\section{Conclusion}

The place of a complex mathematical model of the control object in the design of high-performance automated process control systems of the energy industry is described. Using the dynamics model of a drum boiler as an example, the advantages of using a neuro-fuzzy model for testing, debugging, and optimizing control algorithms are shown. The results of the study of the model show the possibility of creating a custom non-linear dynamic simulation model of a drum steam boiler, which with the appropriate software and hardware PTK can be used in industrial control systems for the purpose of controlling the technological parameters of a drum boiler.

\section{REFERENCES}

[1] Aidan, O'Dwyer., Handbook of PI and PID Controller Tuning Rules. 3rd Edition. Dublin: Institute of Technology; Ireland, Imperial College Press, 2009. 529 p.

[2] Astrom K. J. Advanced PID control/ K. J. Astrom, T. Hagglund - ISA (The instrumentation, Systems, and Automation Society), $2006-460$ p.

[3] C. Lu, C. Hsu, and C. Juang, Coordinated control of flexible AC transmission system devices using an evolutionary fuzzy lead-lag controller with advanced continuous ant colony optimization, IEEE Transactions on Power Systems, vol. 28, no. 1, pp. 385-392, 2013.

[4] D. Pelusi and R. Mascella, Optimal control algorithms for second order systems, Journal of Computer Science, vol. 9, no. 2, pp. 183-197, 2013.

[5] D. Pelusi, PID and intelligent controllers for optimal timing performances of industrial actuators, International Journal of Simulation: Systems, Science and Technology, vol. 13, no. 2 , pp. $65-71,2012$

[6] Demchenko, V.A., Automation and modeling of technological processes at nuclear power plants and thermal power plants / V. A. Demchenko. - Odessa: Astroprint, 2001. - $308 \mathrm{p}$

[7] Pletnev, G.P., Automation of Technological Processes and Productions in Heatand-Power Engineering. 4th Edition. Moscow: Publishing House Moscow Power Engineering Institute, 2007. $-352 \mathrm{p}$.

[8] Rotach, V.Ya., The Theory of Automatic Control. Moscow: Publishing House Moscow Power Engineering Institute, 2008. - $396 \mathrm{p}$

[9] Siddikov I.X., Iskandarov Z., Synthesis of adaptive-fuzzy control system of dynamic in conditions of uncertainty of information // International Journal of Advanced Research in Science, Engineering and Technology. Vol. 5. Issue 1. January 2018 y. pp. 5089-5093.

[10] Siddikov I.X., Umurzakova D.M., Adaptive neuro-fuzzy regulating system of the temperature mode of the drum boiler // International Journal of Advanced Research in Science, Engineering and Technology. Vol. 6. Issue 1. January 2019 y. pp.7869-7872.

[11] Soroko, E.M., Golden Sections, Processes of Self-Organizing and Evolution in Systems: Introduction into the General Theory of System Harmonizing. Moscow: KomKniga, 2006. -264 p.

[12] T. Kim, I. Maruta, and T. Sugie, Robust PID controller tuning based on the constrained particle swarm optimization, Automatica, vol. 44, no. 4, pp. 1104-1110, 2008.

[13] Abrukov V.S. The use of data mining tools for the study of incompletely defined systems / Abrukov V.S., Ya.G. Nikolaeva, D.N. Makarov and etc. // Bulletin of the Chuvash University. 2008. № 2. P. 233-241.

[14] Eremin E.L. Adaptive shunting in control systems of non-minimum phase objects / E.L. Eremin // Informatics and control systems.2001. №1. P.74-82.

[15] Eremin E.L. Discrete-continuous system of adaptive temperature control of a superheater / E.L. Eremin, D.A. Telichenko, L.V. Chepak// Informatics and control systems. Blagoveshchensk, 2004. P. 117-129.

[16] I.X. Siddikov, X.A.Bakhrieva, D.M.Umurzakova Modeling a fuzzy adaptive temperature control system of a heat power facility / «Problems of computer science and energy» №1, 2019 P. $40-47$

[17] Meerov M.V. Adaptive Compensators with Smith Predictor / M.V. Meerov // Automation and telemechanics.2000. № 1 . P. $125-135$

[18] Rotach V.Ya. Theory of automatic control of heat and power processes / V.Ya. Rotach M.: Energoatomizdat, 1985. 296 p.

[19] I.X.Siddikov, D.B.Yadgarova, X.A.Bakhrieva, Synthesis of modeling control algorithms for multilevel dynamic objects / Bulletin of TUIT 2018, №1 (45) P.89-95 